\title{
Family Hardiness in Patients with Heart Failure: Exploring Protective Factors and Identifying the Mediator
}

This article was published in the following Dove Press journal: Psychology Research and Behavior Management

\author{
Yuanyuan Peng' \\ Jie Wang' \\ Guozhen Sun ${ }^{1,2}$ \\ Shenxinyu Liu' \\ 'School of Nursing, Nanjing Medical \\ University, Nanjing, People's Republic of \\ China; ${ }^{2}$ Department of Cardiology, The \\ First Affiliated Hospital, Nanjing Medical \\ University, Nanjing, People's Republic of \\ China
}

Background: Struggling with heart failure (HF) may be a distressful experience for the entire family. As a key variable contributing to positive family functioning, family hardiness can protect against HF-related harm. Thus, recognizing factors associated with family hardiness could promote strategies that enable successful adaptation to HF. This study aimed to explore protective factors linked to family hardiness among HF patients.

Patients and Methods: A cross-sectional study was undertaken in 2020 among $167 \mathrm{HF}$ patients in Nanjing, China. The study measures comprised a self-designed general information questionnaire, the Family Hardiness Index, the Mutuality Scale, the Positive and Negative Affect Scale, and the Simplified Coping Style Questionnaire. The data analysis was performed using IBM SPSS, version 25 and comprised Pearson's correlation analysis, a multiple linear regression model, and an analysis of mediating effects.

Results: The average Family Hardiness Index score for the $167 \mathrm{HF}$ patients was $57.95 \pm$ 11.41. The multiple linear regression analysis revealed that mutuality, active coping style, and positive emotions of HF patients positively predicted family hardiness $(\beta=0.359,0.308$, and 0.215 , respectively; all $P<0.05$ ). Mutuality between patients and family members had partial mediating effects between active coping style, positive emotions, and family hardiness.

Conclusion: Our results revealed that patients' active coping styles, positive emotions, and mutuality were protective factors associated with family hardiness. In light of our findings, we suggest that active coping strategies, positive emotions, and, especially, closer relationships within families should be encouraged during the rehabilitation and follow-up care of HF patients.

Keywords: family hardiness, protective factors, mutuality, mediator, heart failure

\section{Introduction}

Heart failure (HF) has been described as "the unconquered iceberg" of cardiovascular disease in the 21 st century, affecting almost 38 million families worldwide and 13.7 million families in China. ${ }^{1,2}$ Influenced by Confucian cultural values of familism and collectivism, ${ }^{3}$ Chinese people tend to treat $\mathrm{HF}$ as a central family event, usually investing substantial amounts of time and resources into handling this disease. The vast majority of stable HF patients in China choose to recuperate at home. ${ }^{4}$ However, HF is a prototypical chronic disease, entailing a rehabilitation process that is generally long, slow, unstable, and complex. ${ }^{2}$ Over time, this enduring stress could pose a significant challenge for families, with inevitable
Correspondence: Guozhen Sun School of Nursing, Nanjing Medical University, Nanjing, People's Republic of China

Tel $+86 \quad$ I385I769549

$\mathrm{Fax}+86256830348$

Email gzsun100@I26.com 
effects of reduced family functioning and adaption. It has been shown that positive family functioning is an essential element in the treatment of HF, which is associated with medication adherence, self-care behaviors, mortality, and morbidity among patients with HF. ${ }^{5}$ Hence, an assessment of a key variable of positive family functioning along with associated protective factors could yield useful information that enables the identification of families with support needs and those that are resilient or hardy. ${ }^{6}$

Family hardiness is a key variable contributing to positive family functioning, which has been defined as a family's ability to work together cohesively, combatting stressors and finding solutions to problems. ${ }^{6}$ Family hardiness comprises three key elements: perceiving changes as challenges, commitment to life, and a sense of control over life events. ${ }^{7}$ The Resiliency Model of Family Stress posits that family hardiness is an important resistance and a family resource that plays a fundamental role in successful adaptation. ${ }^{8}$ Previous studies have shown that higher levels of family hardiness are associated with lower levels of fear of disease recurrence, ${ }^{9}$ higher levels of psychological resilience, and more successful family adaption. ${ }^{8,10,11}$ However, within the medical domain, most studies about family hardiness have tended to focus on families with ill or disabled children or patients with malignant tumors rather than those with common chronic diseases such as HF, chronic obstructive pulmonary disease, and diabetes. Notably, these types of diseases require enduring or lifelong adaption. To mitigate the adverse physical, psychological, and behavioral effects of these chronic diseases on family members, it is therefore necessary to gain a deeper understanding of the capabilities or strengths (ie, resilience) of the entire family that are constitutive of family hardiness. $^{6}$

The identification of protective factors by health professionals is essential for developing interventions that promote family hardiness. Some studies have found that the active coping styles of parents or children are positively correlated with family hardiness/positive family functioning in families with sick children. ${ }^{6,12-14}$ When patients exhibit active coping strategies relating to their illnesses, they as well as their family members may also exhibit positive functioning (eg higher levels of selfefficacy and adaption $)^{6,13,15}$ that can boost the hardiness of all family members. Therefore, we anticipated that patients demonstrating an active coping style would exhibit higher levels of family hardiness in the face of HF.
The second positive psychological indicator that we investigated was positive emotions. A previous review found that positive emotions (eg, confidence, humor, hope, and courage) were among the key factors promoting family resilience. ${ }^{16}$ Moreover, McCubbin suggested that family hardiness plays a central role in the process of developing family resilience. ${ }^{7,17}$ Thus, positive emotions and family hardiness appear to be linked. Accordingly, we posited that patients who were inclined toward positive emotions would score higher in terms of family hardiness.

Mutuality, which refers to the quality of interactions among individuals, ${ }^{18}$ was another specific variable of interest in this study. Studies have shown that crises and stress may not only derail family functioning but may also affect relationships among family members. ${ }^{19}$ Thus, relationships and family hardiness are equally important within family caregiving research. ${ }^{20}$ According to the literature, the quality of relationships within a family contributes to resilience and adaptability, ${ }^{21}$ which may be beneficial for strengthening the family structure and boosting family hardiness in the context of $\mathrm{HF}^{5}$

Coping styles and emotions have also been identified as important elements associated with relationship quality within the literature. ${ }^{22}$ Because mutuality is considered a kind of positive relationship quality, ${ }^{18}$ it may also be affected by an individual's coping style or emotions, ultimately influencing family hardiness. Understanding the interactions between these variables may pave the way for improving successful coping and adaption strategies within the families of HF patients. Moreover, previous studies suggest that mutuality occupies a pivotal position within family caregiving research and is usually considered as a mediator that promotes positive outcomes. ${ }^{18,23}$ Therefore, we hypothesized that mutuality could also function as a mediator between positive psychological variables (eg, active coping styles and positive emotions) and family hardiness. However, this relationship has rarely been studied in adults with HF. Consequently, this study had the following objectives: (1) to explore levels of family hardiness in patients with HF, (2) to assess the impacts of an active coping style, positive emotions, and mutuality and their contributions to family hardiness, and (3) to determine whether mutuality plays a mediating role between an active coping style, positive emotions, and family hardiness.

\section{Methods}

This cross-sectional study was conducted in a Grade A hospital in the city of Nanjing in Jiangsu Province, 
China, from May 20, 2020 to October 31, 2020. The research was approved by the clinical research ethics committee of the First Affiliated Hospital of Nanjing Medical University [approval number: 2020-SR-068]. In general, the sample size in a multiple linear regression should be at least 5-10 times greater than the number of independent variables. ${ }^{24}$ This study had approximately 17 variables. However, taking into consideration nonresponding subjects, the final estimated sample size was 165 respondents.

\section{Participants}

We applied convenience sampling to recruit patients. All of our participants were recruited from the Department of Cardiovascular Medicine at the First Affiliated Hospital of Nanjing Medical University. Patients were considered eligible for the study if they met the following criteria: (a) able to read and write Chinese, (b) at least 18 years old and able to provide written consent, (c) diagnosed with HF according to the HF guidelines, (d) categorized in the New York Heart Association (NYHA) classes II-IV, (e) lived with at least one family member, and (f) were participating voluntarily in this study. The exclusion criteria were as follows: (a) patients with a history of acute myocardial infarction in the last month, (b) patients with psychiatric diagnoses or cognitive impairment, and (c) comorbidity of other severe somatic diseases, such as cancer and multiple organ failure.

\section{Procedure}

Clinical data, such as the left ventricular ejection fraction (LVEF) and the NYHA functional class of patients, were collected from medical records by the lead researcher. Other data were collected by two trained registered nurses using paper questionnaires. At the beginning of the survey, the nurses explained the purpose and significance of the study to the patients, assuring them that all of the information that they provided would remain anonymous and confidential. Participants were given 15-20 minutes to complete the questionnaires and informed consent form. If they required clarification of any issues relating to the study, they could approach the trained data collectors. To ensure that the data were of high quality, all of questionnaires were reviewed and checked for completeness on the spot. A total of 170 questionnaires were distributed and completed on site, and 167 valid questionnaires were returned (an effective response rate of $98.2 \%$ ). This study was conducted in accordance with the principles of the Declaration of Helsinki.

\section{Instruments}

\section{The Self-Designed General Information Questionnaire}

This questionnaire contained items on the sociodemographic and clinical characteristics of the participants, including sex, age, marital status (married, unmarried, divorced, or widowed), education level (primary school and below, middle school, high school or secondary technical school, junior college, or university and above), work status (working or not working/retired), place of residence (city, town, or countryside), and monthly income in Chinese yuan $(<2000,2000-4000,>4000)$.

\section{Family Hardiness Index}

The Family Hardiness Index, which was, developed and tested by McCubbin, ${ }^{17}$ was used to evaluate family hardiness. This index was translated and modified for the Chinese context by Yang Liu, who administered it among the parents of 330 hospitalized children in $2011 .^{25}$ This Chinese version comprises 20 items, covering the dimensions of commitment, challenge, and control that are rated on a scale of $1-4(1=$ "false" and $4=$ "true"). Total scores for family hardiness, which ranged from 20 to 80 , were calculated by summing the items in each domain. High scores indicated high levels of family hardiness. The Cronbach's alpha value obtained for the total Chinese scale was 0.803 , the split-half reliability value was 0.738 , and the construct validity ranged between 0.506 and 0.810 .

\section{The Mutuality Scale}

The Mutuality Scale, which was developed by Archbold, ${ }^{26}$ was applied to evaluate the positive quality of relationships among family members and patients. A traditional translated Chinese version of the scale was developed by Shyu, who applied it in a study of caregivers of patients with dementia in $2006 .{ }^{27}$ This 15 -item scale, which covers the dimensions of love and affection, shared pleasurable activities, shared values, and reciprocity, is rated on a scale of $0-4(0=$ "not at all" and $4=$ "a great deal"). Total scores ranged from 0 to 60 and individual scores were calculated as the mean of scores for all items. Higher scores indicated a higher quality of the mutual relationship. A mean score of less than 2.5 indicated a weak degree of mutuality. In this study, the Cronbach's alpha value for the total scale was 0.879 . 


\section{Positive and Negative Affect Scale}

The Positive and Negative Affect Scale (PANAS) is a classic and concise scale used to evaluate an individual's real emotions experienced in the previous 1-2 weeks. The Chinese version of PANAS was translated by Li Huang in $2003 .^{28}$ This scale is composed of two subscales, but we only used the positive affect subscale in our survey. This 10 -item subscale comprises 10 adjectives describing positive emotions. Responses were provided using a scale of $1-5$ ( 1 = "very slightly" and $5=$ "very much"). Total scores ranged between 10 and 50, with higher total scores indicating higher levels of positive emotions among respondents. The Cronbach's alpha value for this Chinese version of the PANAS subscale was 0.850 , the test-retest reliability value was 0.470 , and the construct validity ranged between 0.400 and 0.760 .

\section{Simplified Coping Style Questionnaire}

The Chinese version of the Simplified Coping Style Questionnaire, which is used to evaluate an individual's coping style, was translated and modified by Yaning Xie in 1998. ${ }^{29}$ This scale comprises two subscales (active and negative coping styles), although we only used the active subscale in the current survey. This subscale contained 12 items, each of which was rated on a scale of $0-3(0=$ "never" and 3 = "often"). Total scores ranged between 0 and 36, with higher total scores indicating that respondents' active coping styles were strong. The Cronbach's alpha value for this subscale was 0.89 , the test-retest reliability value was 0.89 , and the construct validity ranged between 0.460 and 0.775 .

\section{Statistical Analysis}

All data were processed and analyzed using IBM SPSS version 25. Continuous data were presented as mean \pm (SD) values and categorical data as percentages (\%). The Shapiro-Wilk test was performed to check the normality of data distribution. An independent sample $t$-test and oneway ANOVA were performed to identify differences in family hardiness scores related to the demographic and clinical variables. Pearson's correlation analysis was performed to determine correlations between family hardiness and mutuality, active coping style, and positive emotions of HF patients. Multiple linear regression analysis enabled us to explore protective factors associated with family hardiness among HF patients. We tested the mediating effect analysis using the bootstrap method (5000 runs) by running the PROCESS macro 3.4 (model 4) in the SPSS software. A two-sided $P<0.05$ was considered a statistically significant difference.

\section{Results}

\section{A Comparison of Family Hardiness Scores Among HF Patients with Different Sociodemographic and Clinical Characteristics}

Of the total number of respondents, 51 (30.5\%) were women. The participants' mean age $( \pm$ SD) was $59.43 \pm$ 15.67 years, ranging between 18 and 88 years. Almost two-thirds of the respondents were in the NYHA function class II. The mean LVEF was 55.26\% $\pm 13.20 \%$ (22.9-$72.5 \%$ ). Table 1 shows other demographic and clinical information of the respondents. No significant differences were observed in the family hardiness scores of HF patients with different sociodemographic and clinical characteristics.

\section{Correlations Between Family Hardiness and Mutuality, Active Coping Style, and Positive Emotions Among HF Patients}

The average family hardiness score was $57.95 \pm 11.41$ for the three dimensions examined: commitment (26.87 \pm $5.53)$, control $(16.87 \pm 3.98)$, and challenges (14.21 \pm 3.10). The average scores for mutuality, active coping style, and positive emotions were $2.76 \pm 0.76,23.00 \pm$ 6.69 , and $29.80 \pm 8.47$, respectively. As shown in Table 2, the results of the Pearson's correlation analysis indicated that family hardiness was significantly and positively correlated with mutuality, active coping style, and positive emotions ( $\mathrm{r}=0.610,0.594$, and 0.549 , respectively; all $P<$ $0.001)$.

\section{Multiple Linear Regression Analysis of Predictors of Family Hardiness Among HF Patients}

Mutuality, active coping style, and positive emotions were included in the multiple linear regression model (performed stepwise), while family hardiness was a dependent variable. As shown in Table 3, the results of the multiple linear regression analysis revealed that mutuality, active coping style, and positive emotions of HF patients could positively predict family hardiness $(\beta=$ $0.359,0.308$, and 0.215 , respectively), and the total explanatory quantity of the three variables was $51.1 \%$. 
Table I Comparison of Family Hardiness Scores Among Different Sociodemographic and Clinical Characteristics in Patients with HF

\begin{tabular}{|c|c|c|c|c|}
\hline Variables & N (\%) or Mean (SD) & Family Hardiness & $\mathbf{t} / \mathbf{F}$ & $P$ \\
\hline \multicolumn{5}{|l|}{ Gender/sex } \\
\hline Male & 116 (69.5\%) & $58.13 \pm 12.15$ & 0.302 & 0.763 \\
\hline Female & $5 \mathrm{I}(30.5 \%)$ & $57.55 \pm 9.64$ & & \\
\hline Age & $59.43(15.67)$ & & & \\
\hline$<40$ & $21(12.5 \%)$ & $58.81 \pm 4.88$ & 1.36 & 0.260 \\
\hline $40-60$ & 58 (34.8\%) & $59.69 \pm 6.68$ & & \\
\hline$>60$ & $88(52.7 \%)$ & $56.59 \pm 14.52$ & & \\
\hline LVEF\% & $55.26(13.20)$ & & & \\
\hline$<40 \%$ & $27(16.2 \%)$ & $58.44 \pm 5.02$ & 0.402 & 0.670 \\
\hline $40-49 \%$ & $20(12.0 \%)$ & $59.90 \pm 6.26$ & & \\
\hline$\geq 50 \%$ & $120(7 \mid .8 \%)$ & $57.51 \pm 13.02$ & & \\
\hline \multicolumn{5}{|l|}{ Marital status } \\
\hline Married & I 46 (87.4\%) & $57.77 \pm 11.96$ & 0.139 & 0.936 \\
\hline Unmarried & $6(3.6 \%)$ & $59.5 \pm 6.38$ & & \\
\hline Divorced & $5(3.0 \%)$ & $60.6 \pm 10.60$ & & \\
\hline Widowed & $10(6.0 \%)$ & $58.30 \pm 4.57$ & & \\
\hline \multicolumn{5}{|l|}{ Education level } \\
\hline Primary school and below & $24(14.4 \%)$ & $55.08 \pm 12.74$ & 0.732 & $0.57 \mid$ \\
\hline Middle school & $52(31.1 \%)$ & $57.08 \pm 14.37$ & & \\
\hline $\begin{array}{l}\text { High school or secondary technical } \\
\text { school }\end{array}$ & $5 \mathrm{I}(30.5 \%)$ & $59.20 \pm 6.76$ & & \\
\hline Junior college & $26(15.6 \%)$ & $59.38 \pm 13.02$ & & \\
\hline University or above & 14 (8.4\%) & $59.00 \pm 5.16$ & & \\
\hline \multicolumn{5}{|l|}{ Work status } \\
\hline Working & $46(27.5 \%)$ & $59.93 \pm 6.36$ & -1.368 & 0.173 \\
\hline Not working/retirement & $12 \mid(72.5 \%)$ & $57.21 \pm 12.74$ & & \\
\hline \multicolumn{5}{|l|}{ Place of residence } \\
\hline City & $102(61.1 \%)$ & $58.20 \pm 9.91$ & 0.609 & 0.545 \\
\hline Town & $24(14.4 \%)$ & $55.63 \pm 17.32$ & & \\
\hline Countryside & $4 \mathrm{I}(24.6 \%)$ & $58.7 I \pm 10.75$ & & \\
\hline \multicolumn{5}{|l|}{ Monthly income (Chinese yuan) } \\
\hline$<2000$ & $49(29.3 \%)$ & $56.78 \pm 14.69$ & 0.821 & 0.442 \\
\hline $2000-4000$ & $53(31.7 \%)$ & $57.34 \pm 10.12$ & & \\
\hline$>4000$ & 65 (38.9\%) & $59.36 \pm 9.42$ & & \\
\hline \multicolumn{5}{|l|}{ NYHA functional class } \\
\hline II & III (66.5\%) & $57.95 \pm 12.32$ & 0.084 & 0.920 \\
\hline III & $46(27.5 \%)$ & $58.24 \pm 10.27$ & & \\
\hline IV & $10(6.0 \%)$ & $56.60 \pm 4.38$ & & \\
\hline
\end{tabular}

\section{Outcomes of the Mediation Models}

To test the mediation hypothesis, we set mutuality as a mediator, with active coping style and positive emotions considered as the independent variables and family hardiness as the dependent variable. For both models, bootstrapping (5000 iterations) was performed for random sampling. The results showed that the mediating effect of mutuality on active coping style and family hardiness had a value of 0.345 . Furthermore, a zero-value did not feature in the $95 \%$ CI [0.070-0.337], indicating that the mediating effect was significant. The direct effect of an active coping style on family hardiness remained significant after controlling for 
Table 2 Correlation Between Family Hardiness and Mutuality, Active Coping Style and Positive Emotions in Patients with HF

\begin{tabular}{|l|l|c|c|}
\hline & & \multicolumn{2}{|c|}{ Family Hardiness (Score) } \\
\hline Variables & Scores, s & $\boldsymbol{r}$ value & $P$ value \\
\hline MS & $2.76 \pm 0.76$ & 0.610 & $P<0.001$ \\
\hline ACS & $23.00 \pm 6.69$ & 0.594 & $P<0.001$ \\
\hline PS & $29.80 \pm 8.47$ & 0.549 & $P<0.001$ \\
\hline
\end{tabular}

Abbreviations: MS, the Mutuality Scale; ACS, active coping style; PS, positive emotions.

Table 3 Multiple Linear Regression Analysis of Predictors of Family Hardiness in Patients with HF

\begin{tabular}{|l|c|c|c|c|c|}
\hline & \multicolumn{5}{|c|}{ Family Hardiness Scores } \\
\hline $\begin{array}{l}\text { Investigated } \\
\text { Factors }\end{array}$ & B & SE & $\boldsymbol{\beta}$ & t value & $\boldsymbol{P}$ value \\
\hline MS & 5.374 & 0.977 & 0.359 & 5.502 & $P<0.001$ \\
\hline ACS & 0.524 & 0.115 & 0.308 & 4.570 & $P<0.001$ \\
\hline PS & 0.289 & 0.091 & 0.215 & 3.197 & $P=0.002$ \\
\hline
\end{tabular}

Notes: $F=10.223, P=0.002, R^{2}=0.520$; adjusted $R^{2}=0.511$.

Abbreviations: $B$, unstandardized coefficients; $\beta$, standardized coefficients; MS, the Mutuality Scale; ACS, active coping style; PS, positive emotions.

mutuality ( $\left.\mathrm{c}^{\prime}=0.666, P<0.001\right)$, indicating that mutuality was a partial mediator (see Figure 1 and Table 4). Similarly, positive emotions also indirectly influenced family hardiness through their effect on mutuality $(\mathrm{a} * \mathrm{~b}=0.290,95 \%$ CI: $0.080-0.333)$ and entailed partial mediation $\left(c^{\prime}=0.450\right.$, $P<0.001$ ) (see Figure 2 and Table 4).

\section{Discussion}

We conducted a survey to assess the family hardiness of HF patients in China and subsequently examined the relationship between family hardiness and active coping style, positive emotions, and mutuality. The results of our analysis revealed a moderate level of family hardiness of HF patients $(57.95 \pm 11.41)$. This finding is similar to those obtained for patients with multiple myeloma (57.65 \pm $7.73)$ and inflammatory bowel disease $(58.61 \pm 5.95)$ in China. ${ }^{9,10}$ There are two possible explanations for this finding. First, the above three diseases may share several similar characteristics, such as a long disease course, frequent recurrence, and incurability. Second, all of these surveys were carried out in China. Within Chinese culture, individuals are inclined to assume responsibility for their

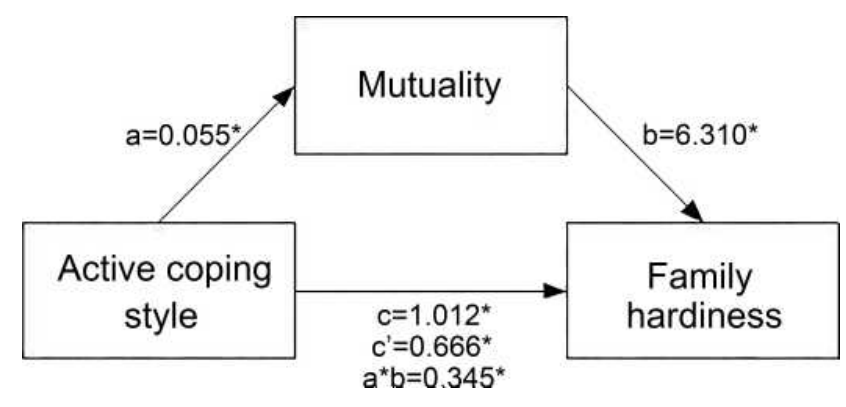

Figure I A mediation model depicting the effect of mutuality on the relationship between an active coping style and family hardiness among heart failure patients. Notes: a: the effects of an active coping style on mutuality; b: the effects of mutuality on family hardiness after adjusting for an active coping style; c: the total effects of an active coping style on family hardiness; c': the direct effects of an active coping style on family hardiness after adjusting for mutuality;a* b: the mediating effects of mutuality in the relationship between an active coping style and family hardiness. $* p<0.05$.

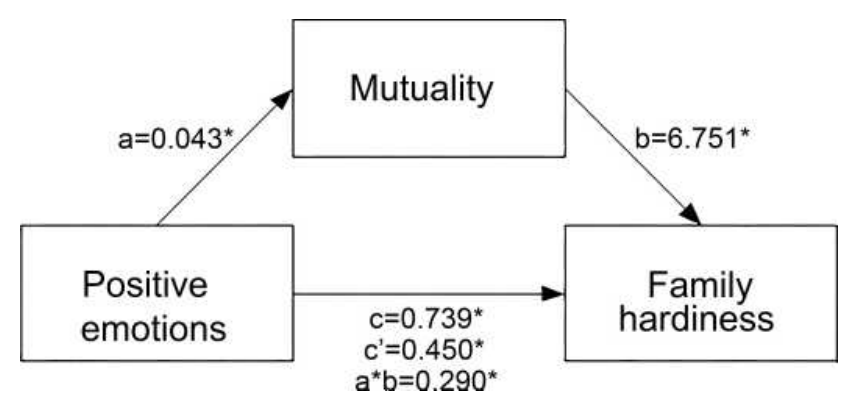

Figure $2 \mathrm{~A}$ mediation model depicting the impact of mutuality in the relationship between positive emotions and family hardiness among heart failure patient.

Notes: a: the effects of positive emotions on mutuality; b: the effects of mutuality on family hardiness after adjusting for positive emotions; c: the total effects of positive emotions on family hardiness; c': the direct effects of positive emotions on family hardiness after adjusting for mutuality; $a * b$ : the mediating effects of mutuality in the relationship between positive emotions and family hardiness. $*_{p}<0.05$.

family members and always collaborate as a unit when facing serious diseases. ${ }^{3}$ This cultural factor could explain why the level of family hardiness was not weak. A moderate level of family hardiness implies the absence of an overly negative reaction within the family in the face of a member's HF, which is indicative of a type of plasticity.

Family hardiness is considered an important family resource that is linked to family well-being and positive functioning in times of stress or illness. ${ }^{30}$ However, from a theoretical perspective, it may not be an ideal target for interventions, given that it is a relatively static or trait-like attribute of a family that may not subject to prompt change. ${ }^{31}$ Therefore, identifying modifiable protective factors relating to family hardiness may prove valuable and practically relevant in clinical practice. While we found that factors such as an active coping style, positive 
Table 4 Outcomes of the Mediation Models

\begin{tabular}{|l|l|l|l|l|l|l|}
\hline \multirow{2}{*}{ Effect } & \multicolumn{2}{|l}{ Active Coping Style } & \multicolumn{2}{l|}{ Positive Emotions } \\
\cline { 2 - 7 } & B (SE) & P-value & Bias-Corrected Bootstrap 95\% Cl & B (SE) & P-value & Bias-Corrected Bootstrap 95\% CI \\
\hline a & $0.055(0.008)$ & $<0.001$ & & $0.043(0.006)$ & & $<0.001$ \\
\hline b & $6.310(0.958)$ & $<0.001$ & & $6.751(0.984)$ & & $<0.001$ \\
\hline c & $1.012(0.107)$ & $<0.001$ & & $0.739(0.088)$ & & $<0.001$ \\
\hline c' & $0.666(0.109)$ & $<0.001$ & & $0.450(0.088)$ & & $<0.001$ \\
\hline a*b & 0.345 & & $0.070-0.337$ & 0.290 & & $0.080-0.333$ \\
\hline
\end{tabular}

Note: Number of bootstrap samples 5000 .

Abbreviation: $\mathrm{Cl}$, confidence interval.

emotions, and mutuality contribute positively to family hardiness, we did not observe any associations between sociodemographic or clinical characteristics and family hardiness.

This study demonstrated that patients' active coping styles were positive predictors of family hardiness. An active coping style refers to a stable behavioral or psychological strategy aimed at changing the nature of the actual stressor or how individuals who are affected think about it, thereby buffering the negative effects of the disease on the patient's family. ${ }^{15}$ In the battle against HF, the patients themselves are undoubtedly the main protagonists (eg, cooperating with exercise rehabilitation, improving medication adherence, keeping optimistic). The strategy chosen by patients to cope with HF and the resulting clinical outcomes may eventually affect the feelings or thoughts (negative or positive) of patients and their family members. It has been established that patients' active coping styles contribute to improved positive attitudes and morale, promote feelings of efficacy, and sustain family cohesion, thereby boosting the resilience or hardiness of the entire family. ${ }^{15}$ Moreover, our findings are supported by those of a previous study, which confirmed that an active coping style is a powerful protective factor relating to family hardiness. ${ }^{12}$ Surprisingly, however, the mean score for active coping style in our study was just $23.00 \pm 6.69$, which is relatively low compared with the average score for China as a whole $(30.10 \pm 8.20)$. HF is a long-lasting stressor for the patient's entire family. In the long run, patients' adoption of an active coping style on its own would likely be beneficial for controlling recurrent symptoms, delaying the progression of the disease, and promoting the mental and physical health of the patients and their family members. Hence, strategies designed to improve patients' active coping styles should be promoted, for example, encouraging patients to be proactive in acquiring knowledge and information about $\mathrm{HF}$ and seeking the support of family members, friends, and health professionals, which would help to boost family hardiness.

The second positive psychological indicator that we investigated was patients' positive emotions, which we also found to be positively associated with family hardiness. According to the literature, positive emotions (eg, joy, humor, courage, and optimism) have been shown to be effective in enabling families to cope with illness. ${ }^{16}$ One study also found that a positive outlook is a key factor related to family resilience because it enables families to view crises as meaningful or comprehensible. ${ }^{16}$ Thus, for patients with strong positive emotions, HF could even be welcomed as a challenge and a new opportunity to bring family members closer together, especially within traditional Chinese families that regard HF as a central family event. Furthermore, the findings of a review indicated that positive emotions enable family members to draw flexibly on high-level connections and to generate wider-thanusual ranges of ideas and percepts, building resilience or compressive capabilities. ${ }^{32}$ In turn, family hardiness is improved and the stress induced by disease is reduced.

In our study, the mean score for positive emotions was only $29.80 \pm 8.47$ compared with an average score of 44.2 \pm 5.3 for China as a whole. Somatic symptoms and psychological distress caused by HF could have been the primary reason for this emotional stress. Hence, strategies such as the application of positive development principles within, for example, positive psychology and social and emotional learning interventions could be applied. These strategies specifically promote enhanced functioning through processes or skills, thereby improving family 
hardiness and patients' positive emotions by fostering a positive family atmosphere. ${ }^{33}$

We also found that for HF patients, mutuality was a protective factor associated with family hardiness. Mutuality refers to the quality of interactions among individuals and is an important consideration in family caregiving research in the context of chronic illnesses. ${ }^{18,20} \mathrm{An}$ emphasis on family relationships has been demonstrated to be important for developing hardy families. ${ }^{16}$ Separate studies by Vellone and Hooker confirmed that higher levels of mutuality corresponded to higher levels of confidence in self-care (self-efficacy) among HF patients. ${ }^{34,35}$ Self-efficacy may further trigger a series of beneficial behaviors, including greater self-control, willingness to learn, and inner strength in dealing with HF. Such changes could serve to buffer stress and promote perceptions of family hardiness among patients. Moreover, mutuality entails feelings of closeness, ${ }^{18}$ thereby improving patients' moods, which, in turn, could positively impact on patients' ratings. In addition, mutuality refers to the positive quality of the relationship between patients and other family members, ${ }^{35}$ which contributes to the creation of a warm atmosphere and establishes a solid family support network under stressful conditions.

Our analysis of mediating effects indicated that mutuality partially mediates between an active coping style, positive emotions, and family hardiness, separately. That is, an active coping style and positive emotions could boost mutuality, which in turn can lead to improved family hardiness in patients with HF. This finding is important and offers insights that can advance family adaption interventions and provide a potential focus for clinical practice, given evidence of the modifiability of mutuality. ${ }^{35}$ Therefore, interventions should especially focus on improving mutuality to strengthen the impacts of an active coping style and positive emotions on family hardiness. For example, during "sit and talk" sessions, family members could be advised to show more empathy toward patients and appreciate all of their efforts to manage HF. Patients could, in turn, express their gratitude to other family members for the daily care and assistance that they offer. ${ }^{35}$ Other strategies, such as enhanced communication, increased engagement in pleasant activities with patients, and restful and relaxing activities have also been shown to result in significantly improved mutuality among patients with chronic illnesses. $^{35}$
Our findings did not reveal any significant relationships between patients' ages, LVEF values and NYHA functional classes, family incomes, and family hardiness. This finding requires further discussion. It is possible that patients in this study were experiencing the exacerbation of HF systems relating to disease severity (including the LVEF value and NYHA functional class), thus requiring symptomatic treatment at the hospital. Their condition may have prompted higher levels of attention and care from family members that enhanced patients' perceptions of family hardiness. One explanation for the lack of association between family income and family hardiness could be that hardiness is a robust concept, referring to a "bounce back" attitude that is not dependent on family income. ${ }^{6}$ However, the effects of patients' sociodemographic features and their clinical characteristics on family hardiness remain unclear. Differences in sample size, criteria for grouping patients and the varieties and characteristic of diseases may also be critical factors contributing to the equivocal results in this area. Notably, one study suggested that whatever effects of hardiness may be on illness, they cannot be readily explained away as simply being reflective of demographic considerations. ${ }^{36}$ In any case, further studies on the relations among sociodemographic features, patients' clinical characteristics, and family hardiness are required.

\section{Limitations of the Study}

Several limitations of this study must be acknowledged. First, we only administered questionnaires to patients and not to their family members because this survey was implemented during the COVID-19 pandemic, and restrictions on family visits were stringent. However, family members' perceptions of coping, emotions, mutuality, and family hardiness may differ from those of patients. To develop a genuine and more comprehensive understanding, further studies focusing on caregivers or other family members of HF patients should be conducted. Moreover, the sample in our study was obtained from a Grade A hospital in Nanjing, in Jiangsu Province, which is considered to be one of the most developed areas in China. Thus, the results may not generalizable to the entire Chinese population which is comparatively more rural and remote. We suspect that families with HF patients in underdeveloped and poorer regions could face more issues in coping with this illness, which may result in lower levels of family hardiness. Multi-local studies should therefore be promoted on a wider scale. Further, patients were undergoing 
medical treatment in hospital during the implementation of this survey. Therefore, these findings may not be generalizable to families with HF patients. Lastly, because of the cross-sectional design of this study, its conclusions regarding causality remain controversial. Hence, longitudinal studies should be conducted to verify them.

\section{Conclusions}

The findings of this study revealed that the family hardiness of HF patients in China was at a moderate level. Patients' active coping styles along with their positive emotions and mutuality were all protective factors associated with family hardiness. Mutuality between patients and family members partially mediated between an active coping style, positive emotions, and family hardiness. Therefore, to improve family hardiness, an active coping strategy, positive emotions, and, especially, closer relationships within families should be encouraged during the rehabilitation and follow-up care of HF patients. Overall, this study not only provides useful insights on the development of strengths and capabilities within families facing HF but it also provides a critical reference for family-centered care of patients with other chronic diseases, such as COPD and diabetes.

\section{Acknowledgments}

We would like to thank all of the volunteers who participated in the present study. This research was supported by grants from the National Natural Science Foundation of China (grant number 72074124).

\section{Disclosure}

The authors report no conflicts of interest relating to this study.

\section{References}

1. Hao G, Wang X, Chen Z, et al. Prevalence of heart failure and left ventricular dysfunction in China: the China Hypertension Survey, 2012-2015. Eur J Heart Fail. 2019;21(11):1329-1337. doi:10.1002/ ejhf.1629

2. Braunwald E. The war against heart failure: the Lancet lecture. Lancet. 2015;385(9970):812-824. doi:10.1016/S0140-6736(14)61889-4

3. Yu X, Stewart SM, Liu IKF, Lam TH. Resilience and depressive symptoms in mainland Chinese immigrants to Hong Kong. Soc Psych Psych Epid. 2014;49(2):241-249. doi:10.1007/s00127-0130733-8

4. Chi C, Zhu JH, Chen H. Effect of comprehensive self-management on improving the prognosis of non-hospitalized heart failure patients. Chin Gen Pract. 2019;22(4):427-432.
5. Shamali M, Konradsen H, Stas L, Østergaard B. Dyadic effects of perceived social support on family health and family functioning in patients with heart failure and their nearest relatives: using the actor-partner interdependence mediation model. PLoS One. 2019;14 (6): $\mathrm{e} 217970$. doi:10.1371/journal.pone.0217970

6. Woodson KD, Thakkar S, Burbage M, Kichler J, Nabors L. Children with chronic illnesses: factors influencing family hardiness. Issues Compr Pediatr Nurs. 2014;38(1):57-69. doi:10.3109/ 01460862.2014.988896

7. Weiss JA, Robinson S, Fung S, et al. Family hardiness, social support, and self-efficacy in mothers of individuals with autism spectrum disorders. Res Autism Spect Dis. 2013;7(11):1310-1317. doi:10.1016/ j.rasd.2013.07.016

8. Ahlert IA, Greeff AP. Resilience factors associated with adaptation in families with deaf and hard of hearing children. Am Ann Deaf. 2012;157(4):391-404. doi:10.1353/aad.2012.1629

9. Hu X, Wang W, Wang Y, Liu K. Fear of cancer recurrence in patients with multiple myeloma: prevalence and predictors based on a family model analysis. Psychooncology. 2020;30:176-184. doi:10.1002/ pon. 5546

10. Li S, Lin Z, Bian QG, et al. Research on resilience and family hardiness of patients with inflammatory bowel disease. Chin Nurs Manage. 2017;17(6):742-746.

11. Huang Y, Huang Y, Bao M, et al. Psychological resilience of women after breast cancer surgery: a cross-sectional study of associated influencing factors. Psychol Health Med. 2019;24(7):866-878. doi:10.1080/13548506.2019.1574353

12. Hong XL, Chen XL. Investigation of family hardiness and its influencing factors in children with refractory nephrotic syndrome. Chongqing Med. 2017;46(21):2952-2954.

13. Compas BE, Jaser SS, Dunn MJ, Rodriguez EM. Coping with chronic illness in childhood and adolescence. Аnnu Rev Clin Psycho. 2012;8(1):455-480. doi:10.1146/annurev-clinpsy-032511143108

14. Thomsen AH, Compas BE, Colletti RB, et al. Parent reports of coping and stress responses in children with recurrent abdominal pain. J Pediatr Psychol. 2002;27(3):215-226. doi:10.1093/jpepsy/ 27.3.215

15. Li X, Guan L, Chang H, Zhang B. Core self-evaluation and burnout among nurses: the mediating role of coping styles. PLoS One. 2014;9 (12):e115799. doi:10.1371/journal.pone.0115799

16. Black K, Lobo M. A conceptual review of family resilience factors. J Fam Nurs. 2008;14(1):33-55. doi:10.1177/1074840707312237

17. McCubbin HI, Thompson AI, McCubbin MA. Family Assessment: Resiliency, Coping and Adaptation: Inventories for Research and Practice. Madison (WI): University of Wisconsin; 1996.

18. Karlstedt M, Fereshtehnejad S, Aarsland D, Lökk J. Mediating effect of mutuality on health-related quality of life in patients with Parkinson's disease. Parkinsons Dis. 2018;2018:1-8. doi:10.1155/ 2018/9548681

19. Greeff AP, Thiel C. Resilience in families of husbands with prostate cancer. Educ Gerontol. 2012;38(3):179-189. doi:10.1080/ 03601277.2010.532068

20. Park EO, Schumacher KL. The state of the science of family caregiver-care receiver mutuality: a systematic review. Nurs Inq. 2014;21 (2):140-152. doi:10.1111/nin.12032

21. Amsters D, Schuurs S, Pershouse K, et al. Factors which facilitate or impede interpersonal interactions and relationships after spinal cord injury: a scoping review with suggestions for rehabilitation. Rehabil Res Pract. 2016;2016:9373786. doi:10.1155/2016/9373786

22. Edwards HB, Ijaz S, Whiting PF, et al. Quality of family relationships and outcomes of dementia: a systematic review. BMJ Open. 2018;8 (1): $\mathrm{e} 015538$.

23. Karlstedt M, Fereshtehnejad S, Aarsland D, Lökk J. Mediating effect of mutuality on caregiver burden in Parkinson's disease partners. Aging Ment Health. 2019;1-8. 
24. Chow SC, Shao J, Wang H, Lokhnygina Y. Sample Size Calculations in Clinical Research. Boca Raton: Chapman and Hall/CRC Press, Taylor \& Francis Group; 2018.

25. Liu Y, Yang JQ, Ye BL, Shen Q, Zhu JM, Chen MQ. Reliability and validity of the Chinese version of Family Hardiness Index. $J$ Nurs Administrat. 2014;14(11):770-772.

26. Archbold PG, Stewart BJ, Greenlick MR, Harvath T. Mutuality and preparedness as predictors of caregiver role strain. Res Nurs Health. 1990;13(6):375-384.

27. Shyu YI, Yang CT, Huang CC, et al. Influences of mutuality, preparedness, and balance on caregivers of patients with dementia. J Nurs Res. 2010;18(3):155-163.

28. Huang L, Yang TZ. Applicability of the positive and negative affect scale in Chinese. Chin Mental Health J. 2003;17(1):54-56.

29. Xie YN. A preliminary study on the reliability and validity of the simple coping style questionnaire. Chin J Clinical Psychol. 1998;6 (2):53-54.

30. Persson C, Benzein E, Årestedt K. Assessing family resources: validation of the Swedish version of the Family Hardiness Index. Scand J Caring Sci. 2016;30(4):845-855. doi:10.1111/scs.12313

31. Shin JY, Steger MF, Shin DW, et al. Patient-family communication mediates the relation between family hardiness and caregiver positivity: exploring the moderating role of caregiver depression and anxiety. J Psychosoc Oncol. 2019;37(5):557-572. doi:10.1080/ 07347332.2019 .1566808
32. Garland EL, Fredrickson B, Kring AM, et al. Upward spirals of positive emotions counter downward spirals of negativity: insights from the broaden-and-build theory and affective neuroscience on the treatment of emotion dysfunctions and deficits in psychopathology. Clin Psychol Rev. 2010;30(7):849-864.

33. Kichler JC, Kaugars AS. Topical review: applying positive development principles to group interventions for the promotion of family resilience in pediatric psychology. J Pediatr Psychol. 2015;40 (9):978-980. doi:10.1093/jpepsy/jsu115

34. Hooker SA, Schmiege SJ, Trivedi RB, Amoyal NR, Bekelman DB. Mutuality and heart failure self-care in patients and their informal caregivers. Eur J Cardiovasc Nur. 2017;17(2):102-113. doi:10.1177/ 1474515117730184

35. Vellone E, Chung ML, Alvaro R, Paturzo M, Dellafiore F. The influence of mutuality on self-care in heart failure patients and caregivers: a dyadic analysis. J Fam Nurs. 2018;24(4):563-584. doi: $10.1177 / 1074840718809484$

36. Kobasa SC, Maddi SR, Kahn S. Hardiness and health: a prospective study. J Pers Soc Psychol. 1982;42(1):168-177. doi:10.1037/00223514.42.1.168
Psychology Research and Behavior Management

\section{Publish your work in this journal}

Psychology Research and Behavior Management is an international, peer-reviewed, open access journal focusing on the science of psychology and its application in behavior management to develop improved outcomes in the clinical, educational, sports and business arenas. Specific topics covered in the journal include: Neuroscience, memory and decision making; Behavior modification and management; Clinical

\section{Dovepress}

applications; Business and sports performance management; Social and developmental studies; Animal studies. The manuscript management system is completely online and includes a very quick and fair peer-review system, which is all easy to use. Visit http://www. dovepress.com/testimonials.php to read real quotes from published authors. 